\title{
Electrophysiological Evidence for the Existence of Both D-1 and D-2 Dopamine Receptors in the Rat Nucleus Accumbens
}

\author{
Francis J. White * and Rex Y. Wang ${ }^{\dagger}, 1$ \\ *Neuropsychopharmacology Laboratory, University of Illinois, Department of Psychology, Champaign, Illinois 61820, \\ and †St. Louis University School of Medicine, Department of Pharmacology, St. Louis, Missouri 63104
}

Extracellular single-unit recording and microiontophoretic techniques were used to characterize the pharmacological properties of dopamine (DA) receptors within the rat nucleus accumbens (NAc), a forebrain structure that receives a dense innervation from mesolimbic DA-containing neurons (A10 DA neurons) located in the ventral tegmental area (VTA). Of the NAc neurons tested, $75 \%$ were inhibited by microiontophoretic administration of the selective D-2 receptor agonist, $L Y-141865$, whereas $38 \%$ were inhibited by microiontophoretic administration of the selective D-1 receptor agonist, SKF-38393. Of the 30 NAc neurons that were tested with both of these agonists, nine were inhibited by both agonists, 11 were inhibited only by LX-141865, five were inhibited only by SKF-38393, and five were not affected by either of these compounds. The inhibitory effects of LY-141865 were blocked and reversed by either intravenous or iontophoretic administration of the selective D-2 antagonist (-) sulpiride, which, however, failed to alter the inhibitory effects of SKF-38393. In contrast, the purportedly selective D-1 antagonist, SCH-23390, selectively hlocked and reversed the inhibitory effects of SKF-38393, suggesting that the two agonists were producing their inhibitory effects via distinct DA receptors. Additional experiments indicated that intravenous administration of LY-141865 caused a biphasic increase/decrease in the activity of NAc neurons. The initial rate increase was apparently due to disinhibition since it was also shown that D-2 DA receptors located on A10 DA neurons exhibited a 3-10-fold greater sensitivity to LY-141865 and DA as compared to the NAc D-2 receptors. These results suggest that both D-1 and D-2 DA receptors exist within the NAc and that agonist occupancy of each of these receptors results in an inhibition of the activity of NAc neurons.

The most widely accepted classification scheme for CNS dopamine (DA) receptors suggests the existence of two distinct receptor subtypes, labeled D-1 and D-2 (Creese et al., 1983; Kebabian and Calne, 1979), which were originally defined on the basis of a stimulatory association with a DA-sensitive ad-

\footnotetext{
Received Apr. 12, 1985; revised July 25, 1985; accepted July 26, 1985.

We wish to thank Pam Dore and Lillian Vickery for technical assistance, and Smith, Kline and French, Schering Corp., Eli Lilly and Co., and Ravizza for generous supplies of drugs. This work was supported by USPHS Grants MH34424 and MH-38794, Research Scientist Development Award Type II MH00378 (R.Y.W.), National Research Service Award MH-08886 (F.J.W.), the Scottish Rite Schizophrenia Research Program N.M.J., U.S.A., the University of Illinois Research Board, a Pharmaceutical Manufacturers Association Foundation Research Starter Grant, and Biomedical Research Support Grant NIH RR-7030.

Correspondence should be addressed to Francis J. White, Ph.D., University of Illinois, Department of Psychology, 603 East Daniel St., Champaign, IL 61820.

1 Present address: Department of Psychiatry and Behavioral Science, Health Sciences Center, State University of New York at Stony Brook, Stony Brook, NY 11794.

Copyright (C) 1986 Society for Neuroscience $0270-6474 / 86 / 010274-07 \$ 02.00 / 0$
}

enylate cyclase or the lack of such an association, respectively. More recently, some D-2 receptors that appear to exert an inhibitory effect on the DA-sensitive adenylate cyclase have been identified (Meunier and Labrie, 1982; Onali et al., 1981; Stoof and Kebabian, 1981). Considerable correlative data attributes most of the physiological, behavioral, and clinical effects of DA neurotransmission to the D-2 receptor whereas, to date, there is considerably less evidence for a role for D- 1 receptors within the CNS (Calne, 1980; Seeman, 1980). However, several recent reports have suggested possible behavioral correlates of D-1 receptor activation, including rotational responses in rats with unilateral nigral lesions (Arnt and Hytell, 1984; Gershanik et al., 1983; Gower and Marriott, 1982; Setler et al., 1978), specific grooming responses (Molloy and Waddington, 1984), and oral dyskinesias (Rosengarten et al., 1983). In addition, one study has reported that D-1 receptor coupling to the adenylate cyclase may be more efficient in schizophrenics (Memo et al., 1983), suggesting that D-1 receptors may play a role in this disorder.

In addition to subdividing DA receptors on the basis of pharmacological profile, one can also distinguish such receptors on the basis of their anatomical location. At least three DA receptors have been identified in this way: postsynaptic DA receptors in apposition to DA nerve terminals, presynaptic DA receptors (autoreceptors) located on DA nerve terminals, and DA autoreceptors located in the somatodendritic areas of DA neurons (see Roth, 1981, for a review). We have employed single-unit recording and microiontophoretic techniques to investigate the physiological and pharmacological characteristics of these anatomically distinct $\mathrm{DA}$ receptors within the mesolimbic and mesocortical DA systems of the rat brain (Mereu et al., 1984; White and Wang, 1984a, c). These A10 DA neuronal systems are thought to be involved in the pathogenesis of schizophrenia (Hokfelt et al., 1977; Matthysse, 1973; Snyder, 1973, 1976; Stevens, 1973) and the therapeutic actions of antipsychotic drugs (Chiodo and Bunney, 1983; White and Wang, 1983a, b). We have recently reported that the somatodendritic DA autoreceptors, which regulate the impulse flow of the majority of mesolimbic A10 DA neurons within the rat ventral tegmental area (Wang 1981b; White and Wang, 1984a), exhibit the pharmacological characteristics of D-2 DA receptors (White and Wang, $1984 \mathrm{c}$ ). In the present experiments, we have attempted to characterize the DA receptors within the rat nucleus accumbens (NAc), which is the major projection site of the mesolimbic A10 DA neurons (Anden et al., 1966; Beckstead et al., 1979; Fallon and Moore, 1978; Nauta et al., 1978; Ungerstedt, 1981). By using the selective D-1 agonist SKF-38393 (Setler et al., 1978; Sibley et al., 1982); the selective D-1 antagonist SCH-23390 (Hytell, 1983; Iorio et al., 1983), the selective D-2 agonist LY141865 (Tsuruta et al., 1981), and the selective D-2 antagonist sulpiride (Creese et al., 1983), we have obtained results that suggest that both D-1 and D-2 DA receptor subtypes may exist within the rat NAc. 


\section{Material and Methods}

\section{Animals and surgical procedure}

All experiments were performed on male Sprague-Dawley albino rats (Sasco, St. Louis, MO) weighing 225-275 gm. The rats were anesthetized with chloral hydrate $(400 \mathrm{mg} / \mathrm{kg}$, i.p.) and mounted in a stereotaxic apparatus. Additional anesthetic was administered as necessary through a lateral tail vein which had been cannulated with a 25 -gauge hypodermic needle. Body temperature was maintained at $36-37^{\circ} \mathrm{C}$ with a thermostatically controlled electric heating pad. In preparation for single-unit recording, a burr hole was drilled in the calvaria overlying the NAc (1.0-2.5 mm anterior to Bregma and 0.8-2.0 mm lateral from the midline suture, according to the atlas of Paxinos and Watson, 1982) or, in some cases, the ventral tegmental area (3.0-3.5 mm anterior to Lambda and $0.5-1.0 \mathrm{~mm}$ lateral) and the dura was retracted. All surgical procedures were performed in strict accordance with the Guiding Principles in the Care and Use of Animals of the American Physiological Society.

\section{Single-cell recording}

Extracellular neuronal signals were recorded through the center barrel of five-barrel micropipettes pulled with a vertical pipette puller and broken back under microscopic control, obtaining an overall tip diameter of ca. 4-7 $\mu \mathrm{m}$. The center barrel was used for recording and was filled with $1 \%$ Fast green dye in $2 \mathrm{M} \mathrm{NaCl}$. The impedance in the center barrel was typically 3-6 M , measured at $60 \mathrm{~Hz}$. In some experiments, single-barrel glass micropipettes were pulled, and broken back to obtain a tip diameter of approximately $1 \mu \mathrm{m}$, and filled as above. Standard recording techniques were used, as previously detailed (White and Wang, $1984 \mathrm{a}, \mathrm{b}, \mathrm{c})$. Electrical signals were amplified with a high-impedance amplifier/filter (bandpass settings $100 \mathrm{~Hz}$ and $3 \mathrm{kHz}$ ), displayed on an oscilloscope, and led into a window discriminator. Integrated-rate histograms, generated by the analog output of the discriminator, were plotted on a polygraph recorder. Electrical signals were also led into an audio monitor.

For recording NAc neurons, electrodes were lowered to $5.5 \mathrm{~mm}$ below the cortical surface and passed via a hydraulic microdrive through the NAc to approximately $7.5 \mathrm{~mm}$ below the cortical surface, where one typically encounters a band of fast-firing neurons $(>20 \mathrm{~Hz})$, which appear to mark the ventral demarcation level between the NAc and the olfactory tubercle (White and Wang, 1984b; Yim and Mogenson, 1982). In some experiments, A10 DA neurons in the ventral tegmental area (VTA) were also recorded. These neurons were identified by their anatomical location within the VTA $(6.0-8.0 \mathrm{~mm}$ ventral from the cortical surface) and by well-established electrophysiological criteria (Bunney et al., 1973; Grace and Bunney, 1983; Wang, 1981a; White and Wang, 1983a), including (1) spontaneous firing rates, typically between 1.0 and $10.0 \mathrm{~Hz}$; (2) either a slow, irregular firing pattern or a slow bursting patten characterized by decreasing spike amplitudes within each burst; and (3) biphasic $(+/-)$ waveforms with relatively long-duration action potentials $(>2.5 \mathrm{msec})$.

\section{Microiontophoresis}

For application of drugs by microiontophoresis, standard five-barrel micropipettes were prepared as previously described (White and Wang, $1984 \mathrm{a}, \mathrm{b}, \mathrm{c})$. Three of the side barrels were filled with drug solutions; the remaining barrel contained a $4 \mathrm{M} \mathrm{NaCl}$ solution and was used for automatic current-balancing (Salmoiraghi and Weight, 1967). Drug solutions used for microiontophoresis were $l$-glutamic acid monosodium salt (Sigma, St. Louis, Mo); SKF-38393 (2,3,4,5-tetrahydro-7,8-dihydroxy-1-phenyl-1H-3-benzazepine; Smith, Kline and French, Philadelphia, PA); LY-141865 (N-propyl tricyclic pyrazole; Eli Lilly, Indianapolis, IN); SCH-23390 (R-(+)-8-chloro-2,3,4,5-tetrahydro-3methyl-5-phenyl-1H-3-benzazepine-7ol-hemimaleate; Schering, Bloomfield, NJ); (-)-sulpiride (Ravizza; Milan), and dopamine $\mathrm{HCl}$ (Sigma). Sulpiride and SCH-23390 were diluted to $0.05 \mathrm{M}$ solutions (pH 3.5-4.5); SKF-38393, LY-141865, and dopamine were diluted to $0.01 \mathrm{M}$ solutions ( $\mathrm{pH} 3.5-4.0$ ). Glutamic acid was diluted to a $0.01 \mathrm{M}$ solution ( $\mathrm{pH} 8.0)$. The tips of all barrels were filled with the various solutions by capillary action provided by strands of fiberglass preloaded into each barrel prior to pulling (Tasaki et al., 1968). Retaining currents of $-10 \mathrm{nA}$ were used between ejection periods for all compounds except glutamatic acid, which was retained with a $+10 \mathrm{nA}$ current and ejected as an anion.

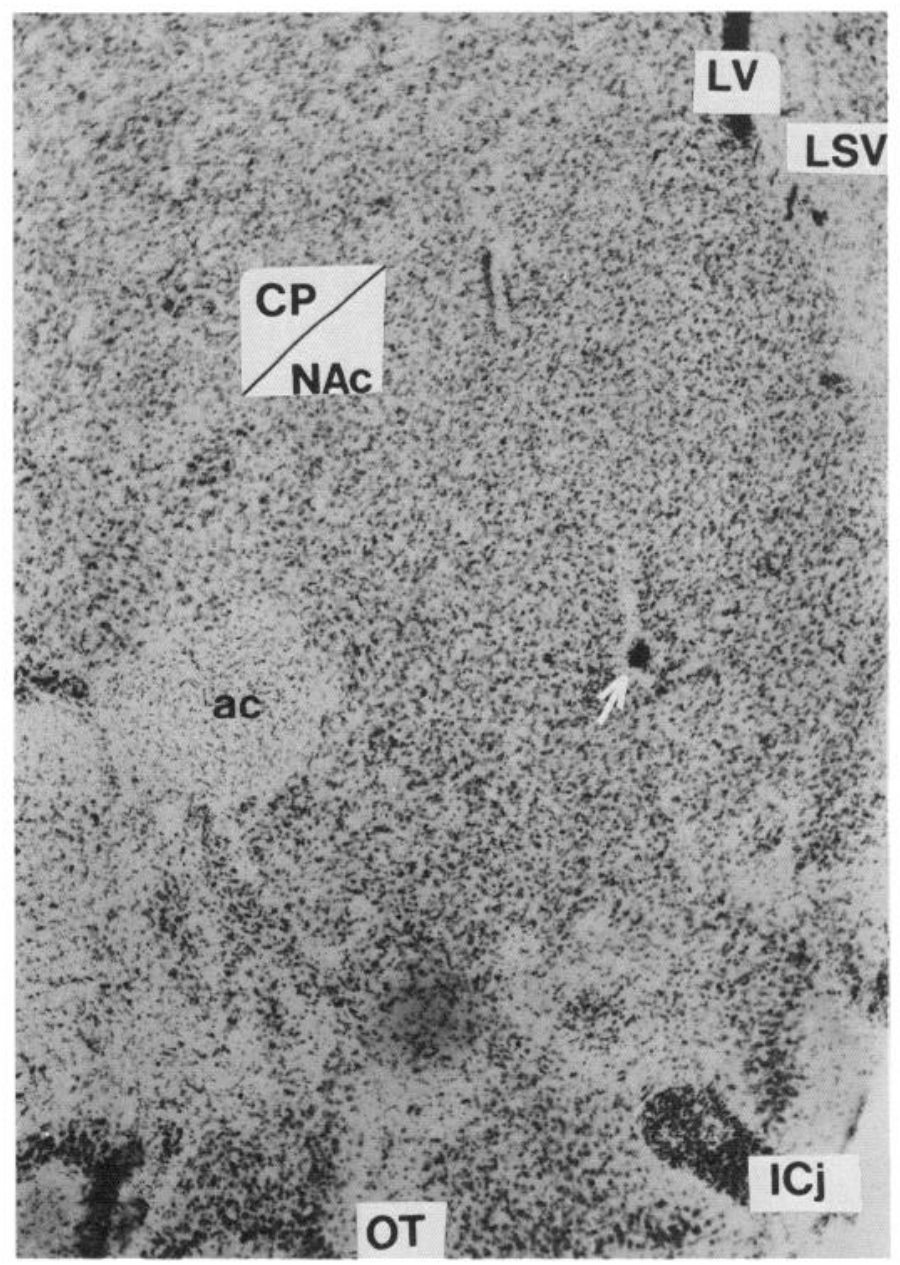

Figure 1. Photomicrograph illustrating a recording site within the caudal nucleus accumbens $(N A C)$. The white arrow is pointing to a recording site that had been marked with a spot of Fast green dye. Note that the orientation of the approximate boundary between the NAc and overlying caudatoputamen $(C P)$ has been indicated by a segment of black line. Labels: $L V$, lateral ventricle; $L S V$, ventral-lateral septal nucleus; $O T$, olfactory tubercle; $I C j$, Island of Calleja; $a c$, anterior commissure.

\section{Intravenous drug administration}

In some experiments, drugs were administered intravenously (i.v.) through the cannulated lateral tail vein. The various DA agonists were injected on a dose regimen in which each dose doubled the previously administered dose. Antagonists were usually injected in a single dose, which was chosen to insure maximum efficacy as determined in previous experiments.

\section{Histology}

At the end of each experiment, the location of the last recorded cell was marked by ejecting the Fast green dye solution iontophoretically $(25 \mu \mathrm{A}$ for $15 \mathrm{~min})$. The rats were then perfused transcardially with normal saline followed by $10 \%$ buffered formalin. The brains were removed and stored in formalin for 24-48 hrs before processing. Frozen serial sections were cut, mounted, stained with cresyl violet and counterstained with neutral red. The dye spot was located using routine light microscopy.

\section{Data analysis}

In the case of spontaneously active NAc cells, determination of percentage inhibition caused by DA agonists was accomplished by comparing the firing rate during the period of iontophoretic application, or following each i.v. injection of the agonist, to a 3-5 min basal period prior to the onset of any drug application. When NAc cells were induced 


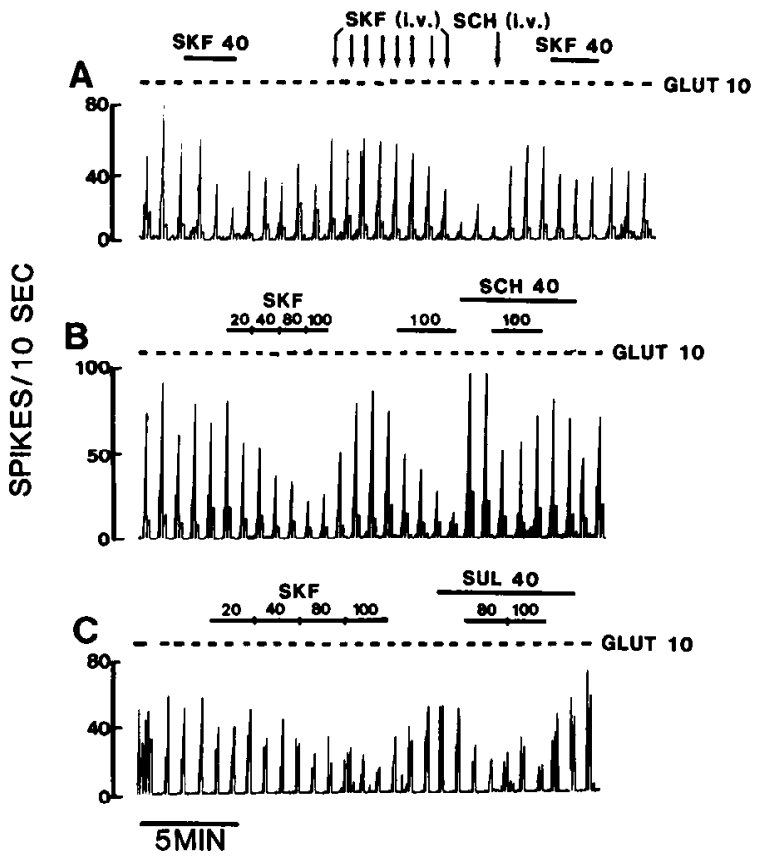

Figure 2. Cumulative rate histograms illustrating three quiescent NAc neurons, induced to fire by microiontophoretic ejection of glutamate (GLUT, $0.01 \mathrm{M})$, and the inhibition of this firing by SKF-38393 $(0.01$ M). $A$, Inhibition of GLUT-induced firing by either microiontophoretically ejected SKF-38393 or i.v. SKF-38393 $(0.01,0.02,0.04 \mathrm{mg} / \mathrm{kg}$, etc., at arrows) and the reversal and prevention of SKF-38393-induced inhibition by i.v. SCH-23390 $(0.5 \mathrm{mg} / \mathrm{kg})$. $B$, Inhibition of GLUTenhanced firing by SKF-38393 and the blockade of this effect by microiontophoretic application of SCH-23390 $(0.05 \mathrm{M})$. $C$, Failure of sulpiride $(S U L, 0.05 \mathrm{M})$ to block the inhibitory effects of SKF-38393. Lines and numbers represent the duration of iontophoretic current and the amount of current in nanoamperes.

to fire by glutamic acid, determinations were made by comparing the degrees of glutamic acid-induced firing in the presence and the absence of the agonist. All statistical comparisons were made using a 1-way analysis of variance (ANOVA), followed by a Newman-Keuls test for comparisons of specific means.

\section{Results}

The boundaries of the NAc are difficult to demarcate with precision, especially the boundary formed between the NAc and the overlying caudate-putamen complex (Domesick, 1981; Heimer et al., 1982; Nauta et al., 1978). In view of this problem, we have used postexperimental histological inspection to insure that the neurons from which we recorded were well within the boundarics of the NAc, as estimated by the atlas of Paxinos and Watson (1982). Figure 1 is a photomicrograph of a coronal section of the rat brain illustrating a representative recording site in the caudal NAc. Note that a line has been displayed on the photomicrograph to illustrate the orientation of the approximate demarcation between the NAc and the caudatoputamen.

As was previously reported for anesthetized preparations (White and Wang, 1984a; Woodruff et al., 1976; Yim and Mogenson, 1982), the NAc contains both quiescent and spontaneously active neurons. The spontaneously active NAc neurons typically exhibit slow firing rates $(0.5-6.0 \mathrm{~Hz})$, characterized by periodic bursts that are separated by long silent periods. In these experiments, we examined the effects of DA agonists and antagonists on both spontaneously active NAc neurons and on NAc neurons that were induced to fire by brief iontophoretic pulses of glutamic acid (GLUT).

Out of 45 NAc neurons tested for responsiveness to microiontophoretic administration of SKF-38393, 17 (38\%) were inhib-

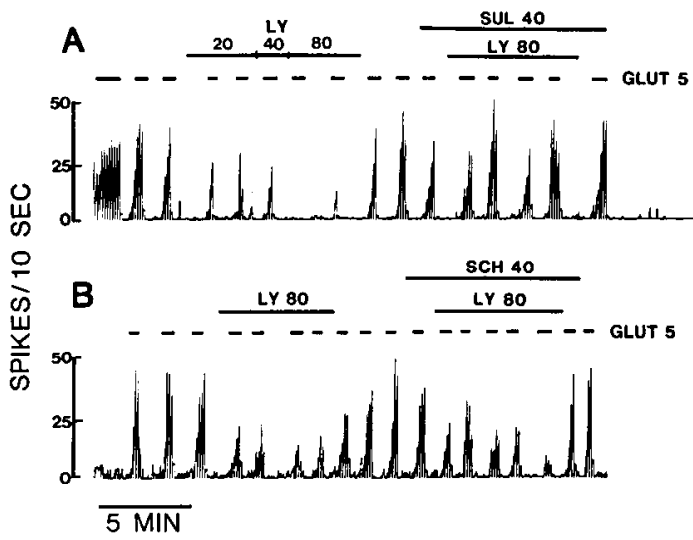

Figure 3. Cumulative rate histograms illustrating the inhibitory effects of iontophoretically ejected LY-141865 $(0.01 \mathrm{M})$ on the GLUT-induced firing of two NAc neurons. $A$, Sulpiride $(S U L ; 0.05 \mathrm{M})$ significantly attenuated the inhibitory effects of LY-141865. B, Failure of SCH$23390(0.05 \mathrm{M})$ to block the inhibitory effects of LY-141865. See Figure 1 legend for further details.

ited at ejection currents of 20-100 nA; both GLUT-driven (Fig. 2) and spontaneous activity (Fig. 4) were inhibited. In addition, intravenous (i.v.) injections of SKF-38393 $(0.01-2.5 \mathrm{mg} / \mathrm{kg}$ ) also inhibited both types of NAc neuronal activity $(n=9$; Figs. 2 and 4). These inhibitory effects of SKF-38393 were significantly $(p<0.01)$ attenuated by either i.v. injection $(0.5 \mathrm{mg} / \mathrm{kg})$ of SCH-23390 ( $n=5$; Figs. $2 A, 4, A$ and $D$ ) or concurrent iontophoresis of this D-1 antagonist $(n=4$; Fig. $2 B)$. In contrast, iontophoresis of the selective D-2 antagonist, sulpiride, failed to alter the rate-suppressant effects of SKF-38393 ( $n=4$; Fig. 2C).

Experiments conducted with the D-2-selective agonist LY141865 revealed that this compound also inhibited the activity of a subset of NAc neurons when administered via iontophoresis (20-80 nA). Of the 40 NAc neurons studied, LY-141865 inhibited the activity of $30(75 \%)$. This effect was also observed on both GLUT-driven (Fig. 3) and spontaneously active (Fig. $4, B$ and $C$ ) NAc neurons. The inhibitory effects of LY-141865 were attenuated by concurrent iontophoresis of sulpiride $(n=$ 13; Fig $3 A$ ) and were reversed by i.v. injections $(10.0 \mathrm{mg} / \mathrm{kg})$ of sulpiride $(n=8$; Fig. $4, B$ and $D$ ). In contrast, concurrent iontophoresis of SCH-23390 only minimally reduced (17 $\pm 3 \%$ reversal) the ability of LY-141865 to inhibit NAc neurons $(n=$ 6 ; Fig. $3 B$ ).

Unlike i.v. SKF-38393, which produced only inhibitory effects on NAc neurons, i.v. LY-141865 caused a biphasic increase/decrease on seven of eight NAc neurons tested (Fig. 4, $B$ and $D$ ). Since this i.v. effect differed from the iontophoretic results, which revealed only inhibitory effects of LY-141865, it seemed likely that the initial increase in activity might be due to an indirect rather than a direct effect on the NAc neurons. Onc possible indirect effect that could account for these findings is an initial increase in NAc activity through a process of disinhibition. Such a process would be expected if, as in the nigrostriatal system (Skirboll et al., 1979), the somatodendritic autoreceptors on mesolimbic A10 DA neurons are more sensitive to the inhibitory effects of DA and D-2 DA agonists than are D-2 receptors in the NAc. To test this possibility, we first compared the effects of i.v. LY-141865 on NAc neurons with those on A10 DA neurons. The results of this comparison clearly indicated that i.v. LY-141865 was significantly $(p<0.01)$ more potent at inhibiting A 10 DA neurons $(n=12)$ compared to NAc neurons $(n=8)$, and that the lower doses that effectively reduced A10 DA firing corresponded to those which activated NAc neurons (Fig. 5). We then directly compared the inhibitory potencies 

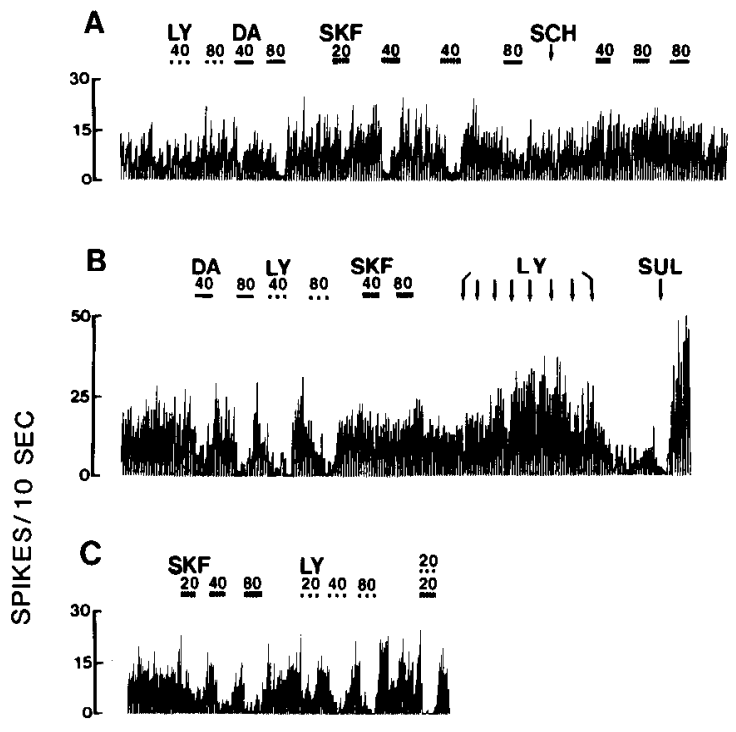

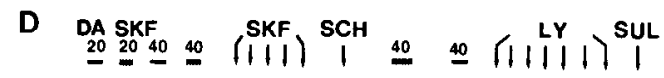

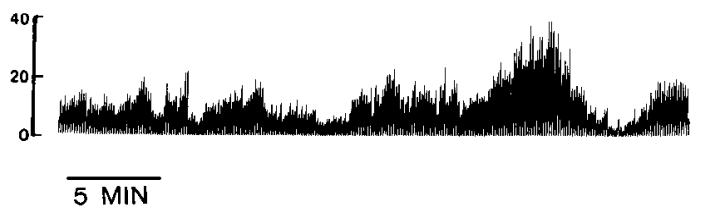

Figure 4. Cumulative rate histograms illustrating the effects of SKF38393, LY-141865, and DA (all at $0.01 \mathrm{M}$ ) on the firing of spontaneously active NAc neurons. $A$, Example of a cell that was readily inhibited by SKF-38393 and DA, but not by LY-141865. Note that SCH-23390 $(0.5$ $\mathrm{mg} / \mathrm{kg}$, i.v.) blocked subsequent attempts to inhibit this cell with either DA or SKF-38393. B, A cell inhibited by LY-141865 and DA, but not by SKF-38393. Note the biphasic increase/decrease in activity caused by i.v. LY-141865 $(0.001-0.128 \mathrm{mg} / \mathrm{kg}$, at arrows $)$ and the reversal of the inhibition caused by i.v. sulpiride $(S U L ; 10.0 \mathrm{mg} / \mathrm{kg})$. C, A cell inhibited by both LY-141865 and SKF-38393, and the apparent additive effects of coadministration of these two agonists. $D$, A cell inhibited by iontophoretic DA and SKF-38393, as well as by i.v. SKF38393 and LY-141865. Note that although i.v. SCH-23390 (0.5 mg/ $\mathrm{kg}$ ) reversed the inhibition caused by i.v. SKF-38393 and attenuated the inhibitory effects of iontophoretic SKF-38393 and DA, i.v. LY141865 still caused the characteristic biphasic alteration in firing that was subsequently reversed by sulpiride $(S U L ; 10.0 \mathrm{mg} / \mathrm{kg})$.

of microiontophoretically administered LY-141865 on NAc neurons and A10 DA ncurons. The results of this comparison also indicated that LY-141865 was significantly $(p<0.01)$ more effective at inhibiting A10 DA neurons than NAc neurons (Fig. $6 A$ ). Comparisons between the responsiveness of A10 DA neurons and NAc neurons to iontophoresis of DA also revealed a similar significant difference between the sensitivities of these neurons to DA-induced inhibition (Fig. 6B); for both LY-141865 and DA, the differences were significant only at the lower iontophoretic currents (10-20 nA). In contrast, since NAc neurons, but not A10 DA neurons, were inhibited by SKF-38393 (Fig. $6 C$; see also White and Wang, 1984c), only inhibitory effects of SKF-38393 on NAc neurons were observed during i.v. injections of this agonist.

Following our initial finding that both SKF-38393 and LY141865 could inhibit NAc neuronal firing, we sought to determine whether the same NAc neurons might be inhibited by both SKF-38393 and LY-141865. Of 30 NAc neurons tested with both agonists, nine were inhibited by both compounds (Fig. 4, $C$ and $D$ ), 11 were inhibited only by LY-141865 (Fig. $4 B$ ), five

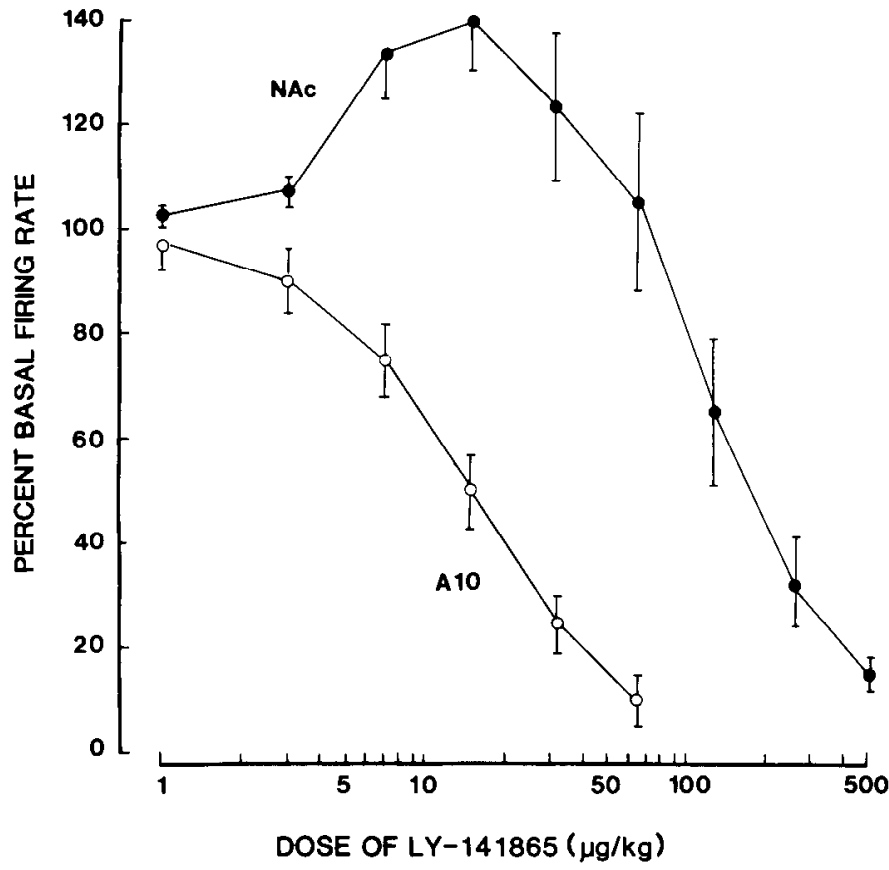

Figure 5. Comparison of the effects of intravenous LY-141865 on the activity of NAc neurons $(n=8)$ and A10 dopamine (DA) neurons ( $n=$ 12). LY-141865 produced a biphasic increase/decrease in the activity of NAc cells, but caused only inhibition of the activity of A10 DA neurons. Note that the lower doses of LY-141865 that decreased A10 DA unit activity were the same doses that increased NAc unit activity.) Data points represent means, bars represent SEM.

were inhibitied only by SKF-38393 (Fig. 4A), and five were not affected by either of these agonists. This lack of effect on some NAc neurons corresponds to previous findings that a small subset of NAc neurons are not sensitive to DA (Akaike et al., 1984; Mogenson et al., 1980; White and Wang, 1984b; Woodruff et al., 1976). Interestingly, when NAc neurons were inhibited by both SKF-38393 and LY-141865, concurrent iontophoresis of both drugs sometimes $(n=3)$ produced inhibition that appeared to be more than simply additive, i.e., the effects of concurrent iontophoresis with $20 \mathrm{nA}$ ejection currents of both SKF-38393 and $L Y-141865$ produced a greater inhibition than a $40 \mathrm{nA}$ current of either agent given alone (Fig. 4A). On two cells, the combined administration of these agonists also prolonged the period of inhibition following current termination.

Combinations of i.v. injections and iontophoretic application of D-1 - and D-2-selective agents on the same NAc neuron indicated that these compounds were, in fact, inducing their effects via interactions at separate receptor populations. Figure $4 D$ shows the results of one such experiment, in which a spontaneously active NAc neuron was inhibited by iontophoretic administration of both DA and SKF-38393. Subsequent i.v. administration of SKF-38393 also inhibited the firing of this neuron, and this effect was reversed by i.v. administration of SCH-23390 (0.5 $\mathrm{mg} / \mathrm{kg}$ ); this antagonist also completely prevented further inhibition during iontophoretic application of SKF-38393 and partially attenuated the inhibitory effect of iontophoretic DA. However, SCH-23390 did not prevent the typical biphasic response observed during i.v. administration of LY-141865. Finally, i.v. sulpiride $(10.0 \mathrm{mg} / \mathrm{kg})$ reversed the inhibition caused by i.v. LY-141865.

\section{Discussion}

The results of these studies indicate the existence of subpopulations of neurons within the NAc that are differentially responsive to the D-1 receptor agonist SKF-38393 and the D-2 receptor agonist LY-141865. The NAc neurons constituted a 
A

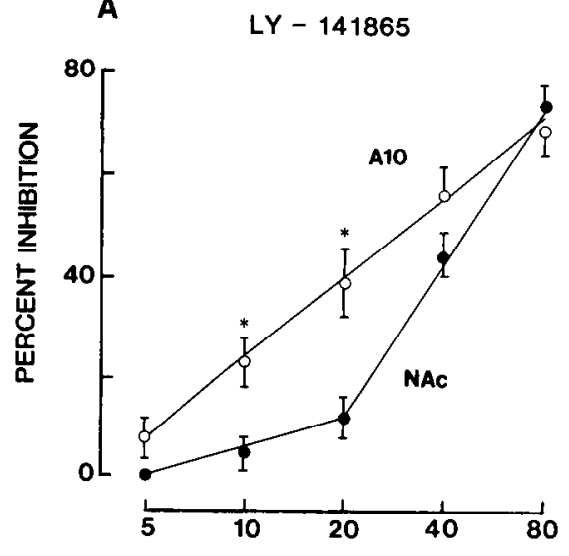

B

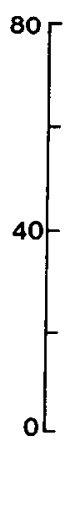

DOPAMINE

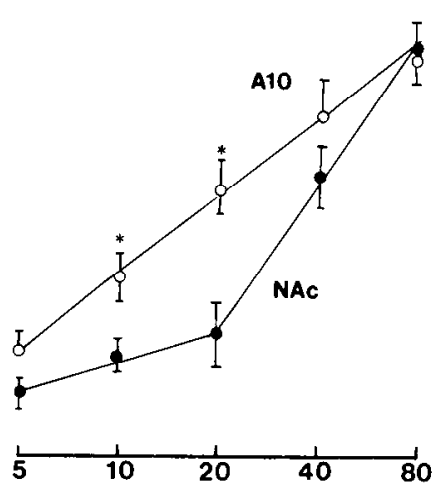

C

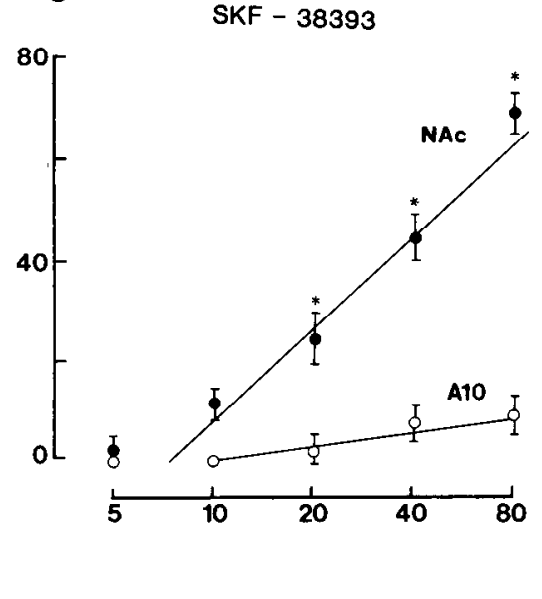

Figure 6. Comparisons of the effects of LY-141865, dopamine (DA), and SKF-38393 (all at $0.01 \mathrm{M}$ ) on the activity of NAc neurons and A10 DA neurons. $A$. Iontophoretic administration of LY -141865 produced only decrements in the activity of both A10 DA neurons $(n=20)$ and NAc neurons ( $n=30$; only LY-141865-sensitive neurons are plotted), but the A10 neurons were significantly more sensitive to low iontophoretic currents than were NAc neurons. $B$, Iontophoretic administration of DA to both NAc neurons $(n=34)$ and A10 DA neurons $(n=24)$ also revealed the significantly greater sensitivity of the A10 DA neurons to DA-induced inhibition. $C$, SKF-38393 readily inhibited the activity of a subset of NAc neurons ( $n=17$; only SKF-38393-sensitive neurons are plotted), but exerted no effect on the activity of A10 DA neurons ( $n=12$ ). Each data point represents the mean percent inhibition; error bars represent the SEM. Asterisks represent points that are significantly different from the corresponding current points $(p<0.01$; ANOVA + Newman-Keuls test).

heterogeneous population in this regard, since some were responsive to only one of these agonists, whereas others were either responsive to both or to neither of them. The fact that both SKF-38393 and LY-141865 inhibited the activity of NAc neurons is somewhat surprising in view of previous biochemical studies suggesting that D-1 and D-2 receptors may exert opposing functions, both on DA-sensitive adenylate cyclase activity (Stoof and Kebabian, 1981) and on the release of cholecystokinin-like immunoreactivity in the rat striatum (Meyer et al., 1984). Of the 30 NAc neurons that have been tested with both SKF-38393 and LY-141865, none have responded in a manner suggestive of opposing functions; in fact, on several neurons, the two agonists appeared to exert synergistic effects. Whether these apparent discrepancies are due to differences in the types of preparations employed (in vivo vs in vitro), the tissue studied (caudate nucleus vs NAc), or some other factor, are essential questions requiring extensive investigation. Current experiments are testing the possibility that antagonistic effects might be observed when LY-141865 and SKF-38393 are concurrently administered to NAc neurons that are selectively inhibited by only one of these agonists, i.e., D-2 agonists might reduce the inhibitory effects of D-1 agonists or vice versa.

To our knowledge, these findings represent the first demonstration of a direct electrophysiological effect of D-1 receptor stimulation. That this is a specific effect on the D-1 receptor is supported by several lines of evidence: (1) the lack of inhibitory effects of the D-2 agonist LY-141865 on certain neurons that were inhibited by SKF-38393; (2) the ability of the selective D-1 antagonist SCH-23390 to attenuate the effects of SKF38393 without exerting significant antagonism of the response to LY-141865; (3) the inability of the D-2 antagonist, sulpiride, to block the effect of SKF-38393; and (4) the independent responsiveness of most NAc neurons to manipulations of these presumed receptor subtypes. Of course, the extent to which we can accept the hypothesis that there are two DA receptors in the NAc is dependent upon the actual pharmacological specificity of the compounds used in these experiments. Although the relative selectivities of LY-141865, SKF-38393, and sulpiride are generally accepted, recent reports suggest that SCH23390 may, in fact, exert D-2 antagonistic effects in addition to its more potent D-1 antagonism (Mailman et al., 1984; Plantje et al., 1984). However, SCH-23390 exhibited excellent pharmacological specificity in the present studies, since it exerted very little antagonism on the electrophysiological effects of LY141865. Moreover, we have previously demonstrated that this compound fails to block the inhibitory effects of DA and a variety of DA agonists on the D-2 DA autoreceptors that regulate the activity of most A10 DA neurons (White and Wang, 1984b). Therefore, our results indicate the presence of functional D-1 and D-2 receptors, as they are currently defined, within the NAc.

Although our findings indicate the existence of both D-1 and D-2 receptors within the NAc, they do not establish that these receptors are present on the NAc neurons themselves. It is possible that the effects observed on NAc neurons during either the D-1 or D-2 receptor manipulations were mediated by DA receptors on afferent terminals. Previous studies using combinations of receptor-binding and selective lesioning techniques have suggested that $D-2$ receptors may exist on both intrinsic neurons and on the terminals of cortical afferents (Garau et al., 1978; Schwarcz et al., 1978). In addition, in vitro release experiments also indicate the existence of DA autoreceptors on the DA terminals themselves (Helmreich et al., 1982; Lehmann et al., 1983; Starke et al., 1983). In contrast, it has been suggested that D-1 receptors exist only on intrinsic neurons (Govoni et al., 1978; Leff et al., 1981; Schwarcz et al., 1978). Selective lesions, combined with electrophysiological experiments, will be required to determine the precise locations of the DA receptors responsible for the inhibitory effects observed in the present studies.

These results supply the first electrophysiological evidence for qualitative differences between the characteristics of DA receptor populations within the presynaptic (somatodendritic) and postsynaptic regions of a DA projection system. Whereas the DA receptors on A 10 DA neurons respond only to D-2 receptor manipulations (White and Wang, 1984c), the DA receptors within the NAc respond to both D-1 and D-2 receptor manipulations. The present experiments also indicate that, as in the nigrostriatal system (Skirboll et al., 1979), the somatodendritic DA autoreceptors on A10 DA neurons are more sensitive to DA and DA 
agonists than are the D-2 DA receptors within the NAc. This apparent difference in sensitivity probably accounts for the finding that, at low i.v. doscs of LY-141865, most NAc ncurons responded with an increase in activity. Since DA appears to be exclusively inhibitory in the NAc (Akaike et al., 1984; Bunney and Aghajanian, 1973, 1975; Woodruff et al., 1976; Yim and Mogenson, 1982), the greater sensitivity of the D-2 DA receptors on the $A 10$ DA neurons projecting to the NAc would cause these neurons to be preferentially inhibited at low doses of the agonist, which would thereby release the NAc neurons from inhibition and result in the increased activity observed. If the D-2 receptors responsible for the inhibitory effects of LY-141865 and DA within the NAc are, in fact, located postsynaptically on the NAc neurons themselves, then these results indicate that the mesolimbic (more accurately, mesoaccumbens) system is characterized by a 3-10-fold greater sensitivity of pre- vs postsynaptic D-2 DA receptors, similar to that previously reported in the nigrostriatal system (Lehmann et al., 1983; Skirboll et al., 1979).

The heterogeneous nature of the responses of individual NAc neurons to D-1- and D-2-selective agonists suggests that these two receptor subtypes may be involved in different aspects of DA neurotransmission. This hypothesis is supported by behavioral results indicating that selective $\mathrm{D}-1$ receptor activation by SKF-38393 fails to induce typical DA-dependent behaviors, such as locomotor activation and stereotypy (Gower and Marriott, 1982; Setler et al., 1978), but can induce oral dyskinesias (Rosengarten et al., 1983) and specific grooming behaviors (Molloy and Waddington, 1984) in rats, both of which are selectively blocked by D-1 antagonists. On the other hand, the fact that some NAc neurons were inhibited by both D-1 and D-2 agonists implies joint regulation of certain aspects of DA neurotransmission. It is unclear at present what such functions might be, although it is interesting that certain behaviors, such as DA agonist-induced rotation in rats with unilateral lesions of the substantia nigra and the reversal of reserpine-induced akinesias are caused by both D-1 and D-2 receptor agonists (Arnt and Hytell, 1984; Gershanik et al., 1983; Gower et al., 1982; Setler et al., 1978). Particularly interesting is the finding that complete reversal of reserpine-induced akinesia is effected only when both D-1 and D-2 agonists are administered (Gershanik et al., 1983). Attributing any of these behaviors to alterations of neuronal activity within the NAc is obviously premature. In fact, many of these behaviors are known to involve the nigrostriatal DA system to a greater extent than the mesolimbic DA system (Kelly et al., 1975). Additional electrophysiological studies are needed to determine the possible existence of D-1 receptors within other DA terminal fields, such as the caudate nucleus and medial prefrontal-anterior cingulate cortices. In addition, since it is generally believed that the NAc is involved in emotive and cognitive aspects of behavior (Matthysse, 1981; Mogenson et al., 1980; Solomon and Staton, 1982; Stevens, 1973), future studies involving these aspects of behavior and their potential mediation by D-1 receptors also seem warranted.

This series of experiments has demonstrated the existence of both D-1 and D-2 DA receptors within the NAc; both appear to mediate neuronal inhibition. In addition, we have also demonstrated a 3-10-fold greater sensitivity of the D-2 DA autoreceptors located on the somatodendritic components of $\mathrm{A} 10$ DA neurons as compared with the D-2 DA receptors within the NAc. Given the current belief that the mesolimbic DA system, in particular the mesoaccumbens DA system, may play an integral role in the pathogenesis of schizophrenia (Matthysse, 1973, 1981; Snyder, 1976; Stevens, 1973) and in the therapeutic effects of antipsychotic drugs (Chiodo and Bunney, 1983; White and Wang, 1983a, b), these findings may have important implica- tions for the future development of new therapeutic agents for the treatment of schizophrenia.

\section{References}

Akaike, A., M. Sasa, and S. Takaori (1984) Microiontophoretic studies of the dopaminergic inhibition from the ventral tegmental area to the nucleus accumbens neurons. J. Pharmacol. Exp. Ther. 229: 859-864.

Anden, N. E., A. Dahlstrom, K. Fuxe, K. Larson, L. Olson, and U. Ungerstedt (1966) Ascending monoamine neurons to telencephalon and diencephalon. Acta Physiol. Scand. 67: 313-326.

Arnt, J., and J. Hytell (1984) Differential inhibition by dopamine D-1 and D-2 antagonists of circling behavior induced by dopamine agonists in rats with unilateral 6-hydroxydopamine lesions. Eur. J. Pharmacol. 102: 349-354.

Beckstead, R. M., V. B. Domesick, and W. J. H. Nauta (1979) Efferent connections of the substantia nigra and ventral tegmental area in the rat. Brain Res. 175: 191-217.

Bunney, B. S., and G. K. Aghajanian (1973) Electrophysiological effects of amphetamine on dopaminergic neurons. In Frontiers in Catecholamine Research, S. H. Snyder and E. Usdin, eds., pp. 957-962, Pergamon, New York.

Bunney, B. S., and G. K. Aghajanian (1975) The effect of antipsychotic drugs on the firing of dopaminergic neurons. In Antipsychotic Drugs, Pharmacodynamics and Pharmacokinetics, G. Sedvall, B. Uvnas, and Y. Zotterman, eds., pp. 305-317, Pergamon, New York.

Bunney, B. S., J. R. Walters, R. H. Roth, and G. K. Aghajanian (1973) Dopamine neurons: Effect of antipsychotic drugs and amphetamine on single cell activity. J. Pharmacol. Exp. Ther. 185: 560-571.

Calne, D. B. (1980) Clinical relevance of dopamine receptor classification. Trends Pharmacol. Sci. $1:$ 412-414.

Chiodo, L. A., and B. S. Bunney (1983) Typical and atypical neuroleptics: Differential effects of chronic administration on the activity of A9 and A10 midbrain dopaminergic neurons. J. Neurosci. 8: 16071619.

Creese, I., D. R. Sibley, M. W. Hamblin, and S. E. Leff (1983) The classification of dopamine receptors: relationship to radioligand binding. Annu. Rev. Neurosci. 6: 43-71.

Domesick, V. B. (1981) Further observations on the anatomy of the nucleus accumbens and caudatoputamen in the rat: Similarities and contrasts. In The Neurobiology of the Nucleus Accumbens, R. B. Chronister and J. B. DeFrance, eds., pp. 147-172, Haer Institute, Brunswick, ME.

Fallon, J. H., and R. Y. Moore (1978) Catecholamine innervation of the basal forebrain. IV. Topography of the dopamine projection to the basal forebrain and neostriatum. J. Comp. Neurol. 180: 545-580.

Garau, L., S. Govoni, E. Stefanini, M. Trabucchi, and P. F. Spano (1978) Dopamine receptors: Pharmacological and anatomical evidence indicate that two distinct dopamine receptor populations are present in the rat striatum. Life Sci. 23: 1745-1750.

Gershanik, O., R. E. Heikkila, and R. C. Duvoisin (1983) Behavioral correlates of dopamine receptor activation. Neurology 33: 1489-1492.

Govoni, S., V. R. Olgiati, M. Trabucchi, L. Garau, E. Stefanini, and P. F. Spano (1978) $\left({ }^{3} \mathrm{H}\right)$-Haloperidol and $\left({ }^{3} \mathrm{H}\right)$-spiroperidol receptor binding after striatal injection of kainic acid. Neurosci. Lett. 8: 207210.

Gower, A. J., and A. S. Marriott (1982) Pharmacological evidence for the subclassification of central dopamine receptors in the rat. $\mathrm{Br}$. J. Pharmacol. 77: 185-194.

Grace, A. A., and B. S. Bunney (1983) Intracellular and extracellular electrophysiology of nigral dopaminergic neurons. 1. Identification and characterization. Neuroscience $10: 301-315$.

Heimer, L., R. D. Switzer, and G. W. Van Hoesen (1982) Ventral striatum and ventral pallidum: Components of the motor system? Trends Neurosci. 5: 83-87.

Helmreich, I., W. Reimann, G. Hertting, and K. Starke (1982) Are presynaptic dopamine autoreceptors and postsynaptic dopamine receptors in the rabbit caudate nucleus pharmacologically different? Neuroscience 7: 1557-1566.

Hokfelt, T., A. Ljumgdahl, K. Fuxe, and O. Johansson (1974) Dopamine nerve terminals in the rat limbic cortex: Aspects of the dopamine hypothesis of schizophrenia. Science 184: 177-179.

Hytell, J. (1983) SCH-23390-The first selective dopamine D-1 antagonist. Eur. J. Pharmacol. 91: 153-154.

Iorio, L. C., A. Barnett, F. H. Leitz, V. P. Houser, and C. A. Korduba 
(1983) SCH 23390, a potential benzazepine antipsychotic with unique interactions on dopaminergic systems. J. Pharmacol. Exp. Ther. 226: 462-468.

Kebabian, J. W., and D. B. Calne (1979) Multiple receptors for dopamine. Nature 277: 93-96.

Kelly, P. H., P. W. Sevoir, and S. D. Iversen (1975) Amphetamine and apomorphine responses in the rat following 6-OHDA lesions of the nucleus accumbens septi and corpus striatum. Brain Res. 94: 507522.

Leff, S., L. Adams, J. Hytell, and I. Creese (1981) Kainate lesion dissociates striatal dopamine receptor radioligand binding sites. Eur. J. Pharmacol. 70: 71-75.

Lehmann, J., M. Briley, and S. Z. Langer (1983) Characterization of dopamine autoreceptor and ${ }^{3} \mathrm{H}$-spiperone binding sites with classical and novel dopamine receptor agonists. Eur. J. Pharmacol. 88: 1126.

Mailman, R. B., D. W. Schulz, M. H. Lewis, I. Staples, H. Rollema, and D. L. DeHaven (1984) SCH-23390: A selective $D_{1}$ dopamine antagonist with potent $\mathrm{D}_{2}$ behavioral actions. Eur. J. Pharmacol. 101: $159-160$

Matthysse, S. (1973) Antipsychotic drug actions: A clue to the neuropathology of schizophrenia? Fed. Proc. 32: 200-205.

Matthysse, S. (1981) Nucleus accumbens and schizophrenia. In The Neurobiology of the Nucleus Accumbens, R. B. Chronister and J. F. DeFrance, eds., pp. 351-359, Haer Institute, Brunswick, ME.

Memo, M., J. E. Kleinman, and I. Hanbauer (1983) Coupling of dopamine D-1 recognition sites with adenylate cyclase in nuclei accumbens and caudatus of schizophrenics. Science 221: 1304-1307.

Mereu, G., M. J. Meldrum, T. C. Westfall, X. T. Hu, and R. Y. Wang (1984) Influences of amphetamine and haloperidol on dopamine terminal autoreceptors. Soc. Neurosci. Abstr. 10: 69.

Meunier H., and F. Labrie (1982) The dopamine receptor in the intermediate lobe of the rat pituitary gland is negatively coupled to adenylate cyclase. Life Sci. 30: 963-968.

Meyer, D. K., A. Holland, and U. Conzelmann (1984) Dopamine D-1-receptor stimulation reduces neostriatal cholecystokinin release. Eur. J. Pharmacol. 104: 387-388.

Mogenson, G. J., D. L. Jones, and C. Y. Yim (1980) From motivation to action: Functional interface between the limbic system and the motor system. Prog. Neurobiol. 14: 69-97.

Molloy, A. G., and J. L. Waddington (1984) Dopaminergic behavior stereospecifically promoted by the D-1 agonist R-SKF-38393 and selectively blocked by the D-1 antagonist SCH-23390. Psychopharmacology 82: 1-11.

Nauta, W. J. H., G. P. Smith, R. L. M. Faull, and V. B. Domesick (1978) Efferent connections and nigral afferents of the nucleus accumbens septi in the rat. Neuroscience 3: 385-401.

Onali, P., J. P. Schwartz, and E. Costa (1981) Dopaminergic modulation of adenylate cyclase stimulation by vasoactive intestinal peptide (VIP) in anterior pituitary. Proc. Natl. Acad. Sci. USA 78: 65316534.

Paxinos, G., and C. Watson (1982) The Rat Brain in Stereotaxic Coordinates, Academic, New York.

Plantje, J. F., F. J. Daus, H. A. Hansen, and J. C. Stoof (1984) SCH 23390 blocks D-1 and D-2 dopamine receptors in rat neostriatum in vitro. Naunyn Schmiedebergs Arch. Pharmacol. 327: 180-182.

Rosengarten, H., J. W. Schweitzer, and A. J. Freidhoff (1983) Induction of oral dyskinesias in naive rats by D-1 stimulation. Life Sci. 33. 2479-2482.

Roth, R. H. (1981) Dopamine autoreceptors: Pharmacology, function and comparison with postsynaptic dopamine receptors. Commun. Psychopharmacol. 3: 429-445.

Salmoiraghi, G. C., and F. Weight (1967) Micromethods in neuropharmacology: An approach to the study of anesthetics. Anesthesiology 28: 54-63.

Schwarcz, R., I. Creese, J. T. Coyle, and S. H. Snyder (1978) Dopamine receptors localized on cerebral cortical afferents to rat corpus striatum Nature 271: 766-768.

Seeman, P. (1980) Brain dopamine receptors. Pharmacol. Rev. 32: 229-313.

Setler, P. E., H. M. Saran, C. L. Zirkle, and H. L. Saunders (1978) The central effects of a novel dopamine agonist. Eur. J. Pharmacol. 50: 419-430.

Sibley, D. R., S. D. Leff, and I. Creese (1982) Interactions of novel dopaminergic ligands with D-1 and D-2 dopamine receptors. Life Sci. 31: 637-645.

Skirboll, L. R., A. A. Grace, and B. S. Bunney (1979) Dopamine auto and postsynaptic receptors: Electrophysiological evidence for differential sensitivity to dopamine agonists. Science 206: $80-82$.

Snyder, S. H. (1973) Amphetamine psychosis: A "model" schizophrenia mediated by catecholamines. Am. J. Psychiatry 130: 61-67.

Snyder, S. H. (1976) The dopamine hypothesis of schizophrenia: Focus on the dopamine receptor. Am. J. Psychiatry 133: 197-202.

Solomon, P. R., and D. M. Staton (1982) Differential effects of microinjections of d-amphetamine into the nucleus acumbens or the caudate putamen on the rat's ability to ignore an irrelevant stimulus. Biol. Psychiatry 17: 743-756.

Starke, K., L. Spath, J. D. Lang, and C. Adelung (1983) Further functional in vitro comparison of pre- and postsynaptic dopamine receptors in the rabbit caudate nucleus. Naunyn Schmiedebergs Arch. Pharmacol. 323: 298-306.

Stevens, J. K. (1973) An anatomy of schizophrenia? Arch. Gen. Psychiatry $29: 117-189$.

Stoof, J. C., and J. W. Kebabian (1981) Opposing roles for D-1 and D-2 dopamine receptors in efflux of cyclic AMP from rat neostriatum. Nature 294: 366-368.

Tasaki, K., Y. Tsukahara, S. Ito, M. J. Wayner, and W. Y. Yim (1968) A simple direct and rapid method for filling microelectrodes. Physiol. Behav. 3: 1009-1010.

Tsuruta, K., E. A. Frey, C. W. Grewe, T. E. Cote, R. L. Eskay, and J. W. Kebabian (1981) Evidence that LY-141865 specifically stimulates the D-2 dopamine receptor. Nature 292: 463-465.

Ungerstedt, U. (1971) Stereotaxic mapping of the monoamine pathways in the rat brain. Acta Physiol. Scand. 367 (Suppl.): 1-48.

Wang, R. Y. (1981a) Dopaminergic neurons in the rat ventral tegmental area. 1. Identification and characterization. Brain Res. Rev. 3: 123-140.

Wang, R. Y. (1981b) Dopaminergic neurons in the rat ventral tegmental area. 2. Evidence for autoregulation. Brain Res. Rev. 3: 141152.

White, F. J., and R. Y. Wang (1983a) Comparison of the effects of chronic haloperidol treatment on $\mathrm{A} 9$ and $\mathrm{Al} 10$ dopamine neurons in the rat. Life Sci. 32: 983-993.

White, F. J., and R. Y. Wang (1983b) Differential effects of classical and atypical antipsychotic drugs on $\mathrm{A} 9$ and $\mathrm{A} 10$ dopamine neurons. Science 221: 1054-1057.

White, F. J., and R. Y. Wang (1984a) A10 dopamine neurons: Role of autoreceptors in determining firing rate and sensitivity to dopamine agonists. Life Sci. 34: 1161-1170.

White, F. J., and R. Y. Wang (1984b) Interaction of cholecystokinin octapeptide and dopamine on nucleus accumbens neurons. Brain Res. 300: 161-166.

White, F. J., and R. Y. Wang (1984c) Pharmacological characterization of dopamine autoreceptors in the rat ventral tegmental area: Microiontophoretic studies. J. Pharmacol. Exp. Ther. 231: 275-280.

Woodruff, G. N., P. S. McCarthy, and R. J. Walker (1976) Studies on the pharmacology of neurons in the nucleus accumbens of the rat. Brain Res. 115: 233-242.

Yim, C. Y., and G. J. Mogenson (1982) Response of nucleus accumbens neurons to amygdala stimulation and its modification by dopamine. Brain Res. 139: 401-415. 